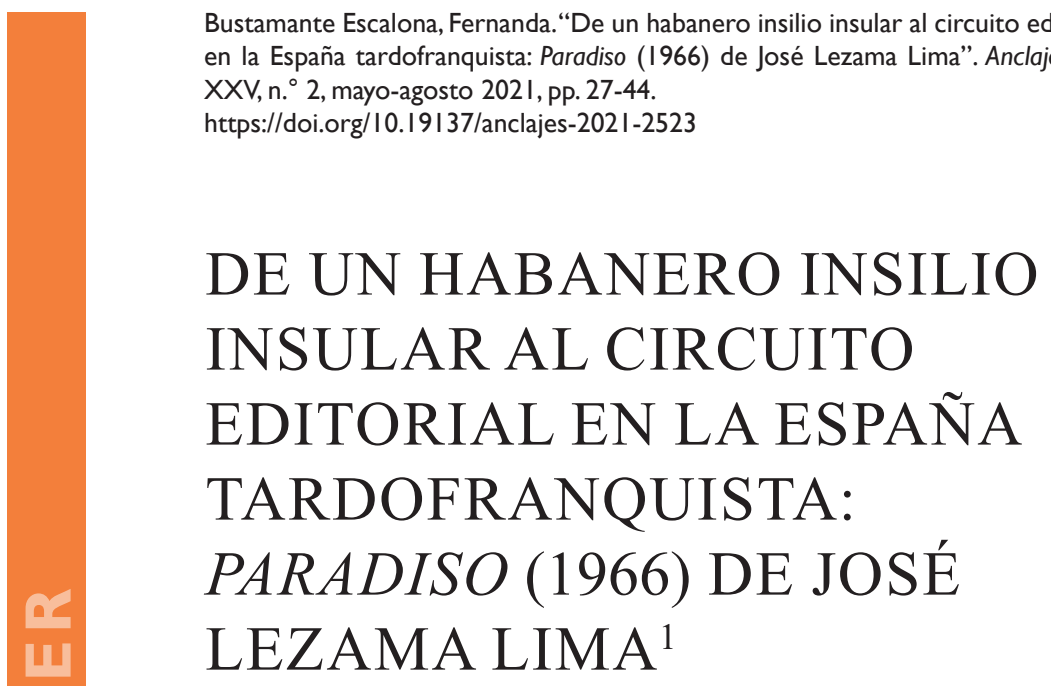

Fernanda Bustamante Escalona

Universidad de Alcalá

España

fernandabustamante@gmail.com

Orcid: 0000-0001-8509-2693

Fecha de recepción: 21/04/2020 | Fecha de aceptación: |4/12/2020

Resumen: Esbozo el recorrido de la llegada de la novela Paradiso (1966) de José Lezama Lima a España, que contó recién en 1976 con una edición española autorizada. Para ello, atiendo a la red de actores culturales de la Península a partir de la correspondencia del cubano con los editores y de los expedientes de censura franquista, albergados en el Archivo General de la Administración, del Ministerio de Educación, Cultura y Deporte en Alcalá de Henares.

Palabras clave: José Lezama Lima; literatura cubana; Paradiso; censura franquista; circuito editorial.

\title{
From the Habana Insular Isolation to the Editorial Circuit of Late Francoism Spain: The Case of José Lezama Lima's Paradiso (1966)
}

Abstract: I trace the arrival of José Lezama Lima's novel Paradiso (1966) to Spain, the authorized Spanish edition appearing in 1976. To this end, I investigate the network of the Peninsula's cultural actors who participated in its publication, using mainly correspondence between the Cuban writer and editors and Francoist censorship files housed

1 Este artículo se inscribe en el proyecto "Literatura hispanoamericana y literatura mundial: análisis de correspondencia múltiple de las redes transatlánticas actuales" (FFI2016-78058-P) del Ministerio de Economía y Competitividad de España (IP: Dunia Gras), del cual formo parte del equipo de trabajo. 
in the General Archive of the Administration of the Ministry of Education, Culture and Sports in Alcalá de Henares.

Keywords: José Lezama Lima; Cuban literature; Paradiso; Francoist censorship; editorial circuit.

\section{De um insilio insular habanero ao circuito editorial da Espanha do franquismo tardio: Paradiso (1966), de José Lezama Lima}

Resumo: Descrevo a trajetória da chegada do romance Paradiso (1966), de José Lezama Lima, à Espanha, que teve uma edição em espanhol autorizada apenas em 1976. Para isso, considero a rede de atores culturais da Península a partir da correspondencia do cubano com os editores e nos documentos de censura franquista, situados no Arquivo Geral da Administração do Ministério da Educação, Cultura e Esporte em Alcalá de Henares.

Palavras-chave: José Lezama Lima; literatura cubana; Paradiso; censura franquista; circuito editorial.

\section{C6 T ezama es un caso de total voracidad" señaló el poeta José Agustín Goytisolo en su introducción al libro Posible ima- gen de José Lezama Lima, la primera obra del cubano publi-} cada en España, en 1969, en la colección de poesía OCNOS. Con la intención de acercarnos a este "caso de voracidad", y consciente de los vacíos y lagunas, presentaré un breve recorrido de la llegada de Paradiso (1966) a España, que contó recién en 1976 con una edición española autorizada. Atenderé a la red de actores culturales de la Península que la protagonizaron y funcionaron como colaboradores, en particular los editores, y al aparato censor franquista, que dificultó esa cooperación, al operar desde la represión y la coerción. Para ello, ha sido fundamental la revisión de la correspondencia del maestro cubano y de los diferentes expedientes de censura franquista de Paradiso que se registran en Espańa, albergados en el Archivo General de la Administración, del Ministerio de Educación, Cultura y Deporte en Alcalá de Henares.

La publicación y recepción de la obra de José Lezama Lima en España se gestó y desarrolló en circunstancias históricas transatlánticas de conmoción y repercusión sociocultural de los años sesenta y setenta, en pleno contexto de la Guerra Fría. Por un lado, y bajo una emergente modernidad literaria latinoamericana, desde Cuba, el régimen de Castro apelaba a una internacionalización cultural de los ideales revolucionarios, así como del pensamiento latinoamericanista, en manos de la élite intelectual y artística cubana y extranjera. Cuba se consolidaba como un foco internacional de la vanguardia política y literaria, y, Casa de las Américas, su institución oficial, como el principal espacio de difusión de la política cultural promovida por La Habana. Sin embargo, a inicios de la década, el emblemático "caso Padilla" (1971), las consiguientes cartas de los intelectuales a Fidel Castro en reacción a la política cultural y el dogmatismo por parte del régimen; los enfrentamientos entre las revistas Casa de las Américas, dirigidas 
desde La Habana por Roberto Fernández Retamar, y Mundo Nuevo, dirigida por Emir Rodríguez Monegal desde París, provocaron, en un importante número de intelectuales, un desencanto, y con ello, el declive de la red cultural y política que se había gestado. Así se inició, en Cuba, lo que Ambrosio Fornet denominó "quinquenio gris": un período en el que el recrudecimiento de la política cultural condujo a la marginación de muchos intelectuales y artistas -ya sea por asuntos políticos y/o estéticos-, a la censura y autocensura, al mismo tiempo que implicó una menor movilidad internacional tanto en los escritores de la isla como en los extranjeros que la visitaron ${ }^{2}$.

Desde la otra orilla, la Espańa del tardofranquismo se encontraba con sus instituciones culturales desmanteladas, sus letras aisladas casi de toda modernidad y con una represión cultural. Así, diversos intelectuales españoles, desde el exilio o dentro del país, buscaron estrategias de resistencia y creación de nuevos espacios de difusión y publicación. Entre ellos, cabe mencionar a los editores, progresistas y de izquierda, que velaron por modernizar, liberar y diversificar a las letras en España, tales como: Carlos Barral (Seix-Barral y Barral editores), José María Castellet (Ediciones 62/Península), Beatriz de Moura (Tusquets), Jorge Herralde (Anagrama), Alonso Carlos (Laia), Esther Tusquets (Lumen), por nombrar algunos; y a la agente literaria Carmen Balcells. Asimismo, surgieron revistas literarias con actitudes disidentes como: Cuadernos del Ruedo Ibérico, Triunfo, Destino e Índice. Todos estos mediadores culturales, aliados en una resistencia al empobrecimiento cultural que se vivía en España, y unidos en un gusto común hacia esta literatura de ultramar, al mismo tiempo que conscientes del potencial económico que había en esa narrativa "otra", se constituyeron en agentes del -emblemático y discutido- proceso de internacionalización y mercantilización de la literatura de la otra orilla: del llamado boom de la literatura latinoamericana.

En esta línea, cabe recordar la participación de otro mediador cultural en España que influyó en este proceso de importación y difusión transcontinental de ideas, modelos y corrientes, y por tanto en la producción literaria e intelectual. Me refiero al aparato censor franquista. Las obras en aquellos ańos se publicaron siguiendo las políticas culturales españolas que se regían por la Ley de prensa e imprenta de 1966, creada por el entonces ministro de Información y Turismo, Manuel Fraga. Esta, entre otras cosas, se caracterizó por aplicar "procedimientos curativos", como el secuestro de las obras, es decir, sacarlas de circulación -lo que significó un importante riesgo económico para las editoriales-, y "procedimientos preventivos", como la -eufemística- "consulta voluntaria" a la que

2 Para mayor información al respecto, véase, entre otros, El 71. Anatomía de una crisis (2013), de Jorge Fornet; y particularmente La polis literaria. El boom, la Revolución y otras polémicas de la Guerra Fría (2018), de Rafael Rojas, en el que su autor establece un recorrido por diferentes hitos políticos-literarios que marcaron esos años, acorde a las fricciones ideológicas y estéticas entre los intelectuales latinoamericanos, especialmente los protagonistas del boom, y la Revolución cubana; y a ese "atajo dogmático de la estrategia editorial cubana" (14). 
eran sometidos los manuscritos por parte de los editores, lo que propició la autocensura y las presentaciones de ejemplares a depósito previo a su distribución. Ante ambas medidas, los "lectores", como fueron llamados los censores, tenían la facultad de aprobar una publicación, así como de sugerir modificaciones, supresiones o simplemente "desaconsejarla" en caso de encontrar "irregularidades", o que su contenido y lenguaje fueran considerados subversivos o contrarios a los principios del régimen. De esta forma, la ley de Fraga funcionó como un dispositivo que institucionalizó y legitimó la censura, el control ideológico e informativo, en la medida en que invistió de legalidad al aparato de represión cultural franquista.

Ante esto, no se puede pasar por alto que a los libros provenientes de la Cuba revolucionaria, los censores les prestaban especial atención ya que, a los clásicos contenidos "conflictivos" (información contraria a España, a Franco y a la monarquía, alusiones que atentaran contra la iglesia y la moral, uso de vocabulario impúdico, etc.), se le sumaron las supuestas irregularidades de tipo ideológico, es decir, si exponían o no ideas de apoyo al régimen de Castro y al comunismo, en el marco, aunque fuera periférico -y castizo-, de la Guerra Fría.

A la hora de cartografiar el entramado de relaciones poéticas transatlánticas entre Cuba y España de mediados de los sesenta, sin lugar a dudas la figura de José Lezama Lima - "el monstruo de Trocadero", como lo llamaban los escritores cubanos- es de gran relevancia. Sobre todo si se tiene en mente que en aquellos años las figuras cubanas de renombre en la Península eran principalmente José Martí, Nicolás Guillén y Alejo Carpentier; mientras que la obra de Lezama tardó más en ser conocida al otro lado del Atlántico. Me remito aquí a las palabras de Rafael Rojas, quien en su artículo "Paradiso, el boom y la Guerra Fría" (2017)3, problematiza el boom en Cuba y enfatiza el interés por parte de la oficialidad cubana por consagrar internacionalmente a estos escritores y sus estéticas, en lugar de figuras como Sarduy, Cabrera Infante, y el propio Lezama, que, como sabemos, también fueron sometidos a una persecución solapada en su propio país. En relación a la recepción de este último por parte del aparato institucional de la isla señaló:

Aunque Lezama no se exilió, la burocracia cultural [cubana] lo percibió como un autor cuyo reconocimiento internacional lo inscribía en una corriente literaria, que estética y políticamente se ubicaba en el polo rival de la Guerra Fría. Los críticos literarios de la revista [Casa de las Américas] -Portuondo, Marinello, Fernández Retamar, Collazos, Rincón...-, que discutían la teoría revolucionaria y socialista de la nueva narrativa latinoamericana jamás vieron Paradiso u Oppiano Licario como ficciones que reflejaran el perfil ideológico, de la literatura como "arma de la Revolución", que se volvió prioritario, sobre todo, a partir del Congreso Nacional de Educación y Cultura en 1971. (Rojas "Paradiso, el boom" 21)

3 Este artículo el autor posteriormente lo publicó como el capítulo VIII de La polis literaria. El boom, la Revolución y otras polémicas de la Guerra Fría (2018), y lleva por título "Paradiso en el boom". 
Es precisamente dentro de este contexto que se llevó a cabo la entrada de las letras "lezamianas" a la Península, las que, al igual que su devenir en la isla, no estuvieron exentas de complicaciones ni "polémicas". He podido constatar que entre 1969 y 1978 se publicaron en Espańa ocho obras del maestro cubano, y que todas las anteriores a la muerte de Franco se sometieron a las consultas de censores, lo que retrasó, en la gran mayoría, su aparición. Estas fueron: Posible imagen de José Lezama Lima (colección ocNos, 1969); La expresión americana (Alianza, 1969); Esferaimagen (Tusquets, 1970); Introducción a los vasos órficos (Barral, 1971); Algunos tratados en La Habana (Anagrama, 1971), Poesía completa (Barral, 1975); Paradiso (Fundamentos, 1976); y, finalmente, su poemario póstumo Fragmentos a su imán (Lumen, 1978)4.

\section{Paradiso y sus tropiezos con el temido "lápiz rojo" de los censores franquistas}

La publicación en España de Paradiso se concretó diez años después de su aparición en Cuba, cuando la obra ya contaba con varias ediciones en América Latina e incluso traducciones (por ejemplo, en Francia e Italia se publicó por primera vez en 1971 en ediciones du Seuil, e Il Saggiatore, respectivamente). Como veremos a continuación, no solo los editores se mostraron sorprendidos - por no decir frustrados- ante la imposibilidad de lograr su publicación, sino que la correspondencia de Lezama da cuenta que ni él mismo estuvo al tanto realmente del devenir de su obra en la Penínsulas.

Si bien este no es el espacio para detenernos en la recepción de Paradiso en Cuba, es oportuno recordarla, ya que esta, como parte de esas poéticas más vanguardistas del boom, también experimentó la desautorización ideológica por parte del régimen (Rojas, La polis 13). Como indica el crítico cubano José Prats Sariol en "Paradiso: recepciones": "Suerte y desgracia, al menos muestra que no ha sido el silencio quien ha acompañado al texto desde su 'escandalosa' aparición en La Habana" (565). Al poco tiempo de haber sido publicada en la isla, en ediciones Unión en 1966, Paradiso fue censurada por su contenido amoral, al

4 Cabe mencionar también que en 1972 Lezama recibió el Premio Maldoror de Poesía creado por Carlos Barral, del cual la edición de Poesía completa era parte del galardón. Esta publicación tardó cerca de tres años en concretarse. Para mayor información, véase el estudio introductorio de El asmático insigne, monstruo de Trocadero. José Lezama Lima y José Agustín Goytisolo (2017) donde esbozo la publicación de estas primeras obras del maestro cubano en España.

5 Desconocemos si las ediciones españolas propuestas para su publicación estaban basadas en la primera de Paradiso (ediciones Unión de La Habana de 1966), o en la segunda autorizada por el autor de 1968, editada en México por ERA, bajo la revisión de Julio Cortázar y Carlos Monsiváis. Recordemos que también ese mismo año en Buenos Aires se publicó la obra en Ediciones La Flor, sin embargo, fue una edición no autorizada ni valorada por Lezama. Así le expresó su descontento ante esta publicación a Emmanuel Carballo a fines de 1968: "La vergonzosa edición argentina se hizo sin el menor uso cortés. No pidieron permiso, no cuidaron el texto y, colmo y pasmo, todavía en estos momentos no me han mandado un solo ejemplar. Da tétanos y desolación" (Lezama, Cartas a Eloísa 363). 
insinuar -en el ya mítico capítulo VIII-, actitudes homosexuales no propias del espíritu del hombre nuevo revolucionario ${ }^{6}$.

En varias ocasiones, el propio Lezama rechazó estas valoraciones malintencionadas en torno a su obra. Así lo vemos, por ejemplo, en esta carta que le envió en junio de 1966 a su hermana Eloísa, quien desde Puerto Rico se desempeñó como su principal agente literaria:

cierto público mojigato se sintió alarmado por ciertos temas que se tratan en el capítulo VIII. Las cosas que sucedían en las escuelas, el despertar del sexo. Creo que tendrán que pasar algunos ańos para que la novela sea captada en su esencia. El coro de ocas se levantó lleno de resentimiento y envidia tronante. Yo creo, sencillamente, que es algo muy importante que ha sucedido en la literatura cubana. [...] Mi única respuesta es seguir trabajando, los venzo porque son unos vagos. (Lezama, Cartas a Eloisa 117)

Por su parte, el escritor cubano José Triana, en la introducción a Cartas a Eloisa y otras correspondencias (1998), da testimonio de estos dictámenes otorgados por la censura cubana a la novela:

A la semana de estar puesta en las librerías, la novela fue recogida, porque, según la versión oficial [...] describía inquietantes y escabrosas situaciones y deformaciones de la conducta sexual [...]. Se consideró que la lectura de la obra podría ser perjudicial para los jóvenes revolucionarios. Incluso se adujo en su contra muestras de "diversionismo ideológico". El escándalo fue tal, que muchos de los amigos de Lezama temíamos por lo que le pudiera suceder. En este contexto se publicó un decisivo ensayo de Julio Cortázar ${ }^{7}$. (111, n. 5)

Desde el otro lado, los "reparos" por parte del dispositivo censor franquista para la aceptación de la publicación íntegra de Paradiso en España fueron constantes y duraderos. Como señala Núria Prats, en "La censura ante la novela hispanoamericana" (2004), "Paradiso, de Lezama Lima, no corrió mejor suerte con la censura española" (196); o, en palabras de Pablo Sánchez, esa "gran novela cubana [...] llegó a España con problemas" $(76)^{8}$.

6 "El 'problemático' Capítulo VIII, ciertamente decisivo en la popularidad de la novela, ha sido víctima de diversas caricaturas. Las más superficiales o interesadamente escandalosas y comercializadas, con las que observan en él elementos pornográficos y hasta una exaltación de las relaciones homosexuales. [...] Detrás de ella se encuentran desde observaciones aberradas, pudicias marginales y poderosas envidias, [...] y aun evidentes manipuleos políticos. [...] Paradiso está libre de 'pecado', goza de perfecta salud sexual" (Prats Sariol, 661).

7 Triana se refiere a "Para llegar a Lezama Lima" (1966) de Cortázar, que fue el primer texto de la crítica en torno a la novela del cubano, cuyo elogio causó gran impacto, sobre todo teniendo en cuenta la estrecha relación del argentino con la Revolución, lo que contribuyó a sacar del silencio a la figura de Lezama, que en ese entonces era un escritor desconocido en el circuito literario hispanoamericano y rechazado por el aparato institucional de la isla.

8 Véase, también, el artículo de Manuel L. Abellán, "La escritura franquista y los escritores latinoamericanos", donde plantea que Paradiso "ilustra ejemplarmente el tratamiento infringido por la censura franquista a uno de los más singulares escritores latinoamericanos" (18). 
La primera huella o indicio en torno al interés por publicar la novela en España la encontramos en la correspondencia del cubano con Carlos Barral, en ese entonces editor del sello Seix Barral; específicamente, en dos telegramas (conservados en el Fondo Personal de José Lezama Lima de la Biblioteca Nacional de Cuba José Martí en La Habana'), fechados el 27 y el 28 de septiembre de 1966, en los que Barral le menciona estar "interesado derechos lengua española novela Paradiso" [sic] y le pide el envío de un ejemplar (Fondo JLL-BNCJM: 654 y 653). Le sigue a estos documentos la carta que Lezama envía a sus hermanas el mismo 28 de septiembre contándoles, con gran entusiasmo, sobre esta petición: "otra noticia sensacional en relación con mi novela Paradiso. La casa Seix Barral, la mejor editora de Espańa, ha solicitado su publicación. Ya tengo en mi poder el cable" (Lezama Cartas 201).

Prácticamente un mes después, el 25 de octubre de 1966, el catalán le envió una carta mecanografiada, con el membrete de Seix Barral, en la que le reafirmaba su interés por adquirir los derechos de la edición de Paradiso para todos los países de lengua castellana excepto Cuba, y le detallaba las condiciones del contrato. Pero no sin advertirle de la presunta negativa que podría dar la censura:

No debo ocultarle que la edición de su libro en España y su difusión en algunos países de América Latina plantea problemas de principio. Ese famoso capítulo octavo, de cuya existencia sabía antes de recibir el libro, augura feroces discusiones con la censura española y me hace temer por la posible reacción de algún juez particularmente apegado a la hipocresía en materia de revelaciones, aunque sean, sarcásticas, sobre las costumbres y los deseos eróticos de las gentes. (Fondo JLL-BNJM: 655)

Sin embargo, al no registrarse ningún expediente de Paradiso abierto por Seix-Barral en el Archivo General de la Administración, que dé cuenta o de que hubo solicitud de consulta voluntaria del manuscrito, o de que el libro haya sido enviado a depósito por la editorial, suponemos que el proyecto se quedó en conversaciones internas entre el autor y el editor, sin llegar a pasar a etapas más formales, en gran parte por los riesgos que implicaba someterla a los certámenes del aparato censor, pero también por la propia salud de Lezama que lo obligaba a tomarse pausas en su trabajo. De hecho, en su epistolario se encuentra una copia en mecanuscrito de una carta que le dirigió a Barral el 3 de octubre de 1967, en la que le aclaró su conocimiento de los procedimientos de la censura y su rotunda negación a intervenir el manuscrito, con la cual, quizás, se dio cierre a este episodio:

Mi distinguido amigo Carlos Barral:

[...] ya Uds. se inquieta al no tener respuesta de las varias veces que se ha dirigido a mí, para conversar del Paradiso.

9 Utilizaré la sigla JLL-BNJM para referirme a los documentos citados que se encuentran en este fondo, y luego el número con el que se encuentran catalogados dichos documentos. 
Desde el primer momento me convencí que no era posible publicar Paradiso en Espańa. Sabemos que la censura lo hubiera impedido, ya que lo ha hecho, con libros menos conflictivos. Yo, en ningún momento estaría dispuesto a publicarlo, mutilando alguna de sus páginas. Es pues imposible conciliar criterios. Además de que hubiera tenido como consecuencia una pérdida de tiempo. [...] (Fondo JLL-BNJM: 1140; subrayado del original)

De acuerdo a los expedientes y carpetas presentes en el Archivo General de la Administración, el primer intento que se registra por publicar en Espańa la obra fue a dos años de su aparición en La Habana. El 11 de noviembre de 1968 José Luis Postigo, en representación de la editorial del País Vasco, Equipo San Sebastián, envió a depósito seis ejemplares de esa edición de Paradiso, "no presentada previamente a consulta voluntaria", e indicó en el formulario del depósito que constaba de 531 páginas y que se publicaría en la colección Escuela Social. Sin embargo, tras ser sometida a la previa evaluación de los censores, la edición fue "objeto de secuestro administrativo", y no solo se dio orden de prohibir su distribución y comercialización en el país, sino que de retirar todos los ejemplares de circulación de las librerías y destruir todos los que estuvieran impresos.

Las causas finales del secuestro de la obra, sustentadas principalmente en su contenido subversivo y pornográfico, se encuentran plasmadas en una carta mecanografiada, albergada en el expediente n. ${ }^{\circ}$ 9.652-68 y fechada en Madrid el 23 de noviembre de 1968. En ella, el entonces ministro de Información y Turismo, Manuel Fraga, se dirige a Antonio María Oriol, Ministro de Justicia, y le comunica:

Con fecha de hoy se ha ordenado por este Departamento otro secuestro: el de la obra "Paradiso", de José Lezama Lima, editada por EQuipo editorial [...]

José Lezama Lima es autor de mucho prestigio literario en Cuba especialmente, pero la morosidad de descripciones eróticas en diversos pasajes de la extensa obra, la hace rechazable pese a las calidades literarias que pueda tener la prosa del autor.

Como verás, cada uno de los libros está en uno de los dos frentes de presión editorial: el ideológico subversivo y el literario pornográfico. (mayúsculas en el original)

La revisión de los expedientes de censura ha permitido constatar que las apelaciones del Equipo editorial San Sebastián en 1968 fueron infructíferas, ya que los revisores continuaron rechazándola por sus "infracciones" a la moral y a las buenas costumbres, por ser una obra de "contenido delictivo" (expdte. n. ${ }^{\circ}$ 9652-68), ante lo cual el sello finalmente canceló su publicación. Asimismo, en la correspondencia del cubano no se ha encontrado ninguna carta que dé cuenta del contacto entre el autor y la editorial, por lo que desconocemos si Lezama estuvo al tanto, o participó, de este proceso de publicación.

Por otro lado, similar fue el resultado del intento hecho por Barral editores, más de cinco ańos después, cuando el sello solicitó, el 22 de septiembre de 1973, la consulta voluntaria de su edición, esta vez compuesta por dos volúmenes de 
295 páginas cada uno, dentro de la colección Hispánica Nova, como se registra en el informe del expediente n. ${ }^{\circ} 10.321-73^{10}$. En esa oportunidad el lector de turno, que atendió ya no solo a asuntos temáticos sino también estilísticos, declaró en el informe a la novela como una obra de "escasa acción, pesada, divagatoria, sin apenas hilo argumental y escrita en un estilo confuso y nebuloso", en la que abundan las "descripciones sexuales, inmoralidades, relaciones homosexuales e irreverencias" (expdte. n. ${ }^{\circ}$ 10.321-73). En el último párrafo, luego de enumerar las páginas en las que se encontraban esos episodios, dictamina:

Hechas las oportunas correcciones en los parrafos [sic] señalados, la novela quedaria [sic] 'limpia' y podria [sic] ser autorizada, si bien perderia [sic] algunos de sus episodios mas [sic] caracteristicos [sic] y quedaria [sic] desdibujado el retrato de algunos de los personajes. AUTORIZADA CON TACHADURAs. (expdte n. ${ }^{\circ}$ 10.321-73; mayúsculas del original)

Más allá de esta sugerencia de censurar fragmentos, que implicaba la intervención de la obra, en el informe final que se le entregó a la editorial, fechado en Madrid el 24 de octubre de 1973, se le comunicó que "no es aconsejable la edición de la obra titulada "PARADISO I Y II" (expdte n. ${ }^{\circ}$ 10.321-73; mayúsculas del original).

En relación a este episodio, no hemos podido acceder a ningún documento que dé cuenta de un contacto entre Barral y Lezama, ya sea en torno a la solicitud de los derechos de edición de la novela o del dictamen otorgado por la censura franquista. De hecho, la correspondencia conservada entre ellos desde 1972 y octubre de 1973 -tanto en el fondo personal del cubano como en los diferentes epistolarios publicados consultados- consta de solo cuatro cartas (una de Barral y tres de Lezama) cuyo tema central es el premio de poesía Maldoror, otorgado en Palmas de Mallorca a Lezama en 1972, y a la posterior publicación de Poesía completa en Barral editores (parte de dicho premio), pero no se hace mención a este intento de publicación de Paradiso ${ }^{11}$.

10 Este expediente nos da cuenta de que Barral, luego de la escisión de la editorial Seix Barral a fines de los sesenta, formalizó su interés por introducir la obra en el circuito editorial español, esta vez en su nuevo sello, sin embargo, y como ya lo había advertido años atrás, continuó sin dar resultados positivos.

Cabe mencionar también que el 27 de mayo de 1970 Barral le escribió a Lezama pidiéndole los derechos de la publicación de la continuación de Paradiso, que en ese entonces llevaba por título Inferno. Sin embargo, la respuesta del habanero, que se registra escrita en letra manuscrita al dorso del folio de la carta de Barral (imaginamos que a modo de copia de la original), no fue positiva dado que la obra aún no estaba terminada: "Querido Carlos Barral: recibí su carta y me apresuro a contestarla. En cable anterior le decía que tardaría la continuación de Paradiso, llámar [ilegible] como en dificultad se llamará, no está terminada. Yo creo que será una de esperar dos o tres años depende de mi salud, y de la continuidad de mi trabajo. Cuando esté la obra le escribiré y le informaré sobre los demás detalles." (Fondo JLL-BNCJM: 656).

11 Estas cartas corresponden a: la de Carlos Barral a Lezama, del 31/05/1972 (Fondo JLL-BNCJM: 1212); y las de Lezama al editor del 26/10/1972, el 17/09/1973 y el 31/10/ 1973 (Fondo JLLBNCJM: 1213, 657 y1214, respectivamente). 
Sin embargo, pese a las negativas, los editores españoles continuaron los esfuerzos por publicar la obra en Espańa, la que, para ese entonces, ya contaba con varias ediciones en Latinoamérica (Unión, 1966; Era, 1968; La Flor, 1968). Así, el tercer intento de publicación, del que se tiene registro en el Archivo General de la Administración, corresponde al de la editorial madrileńa Fundamentos, que entre 1974 y 1976 abrió tres expedientes con sus respectivos envíos a depósitos, no así consultas voluntarias previas. En dichas ocasiones se enfrentaron tanto a instancias de apelación como de silencio administrativo. Esta figura, como ha indicado Cristina Viscaíno, co-fundadora de la editorial, les permitió "obviar la primera censura y darnos un margen para seguir adelante" (en Tena 390), y con ello pudieron poner en circulación la obra en 1974, sin ser retirada ni secuestrada durante esos años de espera de la resolución. La autorización oficial finalmente se obtuvo en 1976, al año siguiente de la muerte de Franco, y poco antes de la muerte de Lezama. En esa ocasión, la burocracia administrativa terminó jugando a favor de la publicación.

El 13 de septiembre de 1974 Viscaíno le envió a Lezama una carta mecanografiada con el membrete de la Editorial Fundamentos, en la que le pedía la autorización para la publicación de Paradiso:

Tenemos el proyecto de dar a conocer al público espańol su obra PARADIso. Como usted ya sabrá actualmente no hay ninguna edición publicada en España y las que existen en otros países de América no llegan prácticamente hasta nosotros, con lo cual una obra de tanta importancia es leída solo por una minoría de nuestro país. [...].

Nos gustaría mucho recibir su autorización a nuestra empresa y nosotros por nuestra parte poder corresponder a su atención. [...] (Fondo JLL-BNJM: 837; mayúscula del original)

Si bien ignoro si hubo o no una respuesta por parte del cubano a la editorial, en los expedientes se constata que el 3 de diciembre de ese año, Cristina Viscaíno, sin pasar por una consulta previa voluntaria, envió los ejemplares de la edición a depósito (de 496 páginas y dentro de la colección Espiral). A los tres días el co-director de la editorial, Juan Serraller Ibáńez, adjuntó al formulario una carta en la que solicitaba la reconsideración de la publicación de Paradiso, bajo el argumento de que los tiempos habían cambiado y que no se explicaba cómo una obra de tal envergadura, con varias ediciones en otros países, no tuviera una espańola:

nos dirigimos a Vd. [...] con el fin de que: esta Dirección solicite ante el Juez del Tribunal de Orden Público autorización para la difusión de la obra [...]. Han pasado ya seis ańos desde su anterior prohibición, durante los cuales el panorama de la sociedad espańola ha experimentado notables cambios, así como señalar que esta obra clásica considerada por la critica [sic] como la novela mayor de toda la literatura hispanoamericana de este siglo no cuente con una edición en Espańa y sí en 16 países. (expdte. n. ${ }^{\circ} 12.628-74$ ) 
Los documentos presentes en el expediente de la Dirección General de Cultura Popular dan cuenta de que inicialmente, a finales de diciembre de 1974, "sin prejuzgar sus innegables valores literarios", se había "acordado mantener el secuestro de la edición del libro", porque en determinadas secciones se vertían "conceptos rayanos en la pornografía que pudieran constituir delito" de acuerdo al Código Penal. Sin embargo, en enero de 1975 se notificó a la editorial que había sido solicitada al Magistrado Juez de Orden Público "la posible autorización para la difusión de la obra por territorio nacional” (expdte. n. $\left.{ }^{\circ} 12.628-74\right)$, ante lo cual quedaron sujetos a la espera de la resolución. Esta situación permitió que el libro continuara siendo distribuido. Si bien, en mayo de 1975 el magistrado juez Rafael Chaparra dejó sin efecto el secuestro de la obra, todo indica que no se le informó a la editorial de esta autorización para su difusión.

Precisamente, ante este silencio administrativo, el 18 de diciembre de 1975, Alicia de Uña Andicobery, en representación de la Editorial Fundamentos, volvió a abrir un expediente (n. ${ }^{\circ}$ 13.838-75), con el depósito de los respectivos ejemplares. No obstante, el Tribunal de Orden Público no notificó ni impugnación ni resolución alguna lo que permitió que la difusión y distribución de la obra se mantuviera. Tras continuar con el desconocimiento de la resolución, de Uña Andicobery, una vez más envió a depósito a Paradiso. Esta vez registrándose como la segunda edición del libro de 1974. Si bien no consta ningún parte entregado al sello en el que se le informara la autorización oficial, se encuentra una carta de marzo de 1976, del jefe del Servicio de Régimen Editorial, Antonio Barbadillo, dirigida al subdirector general de la Promoción y Ordenación Editorial, en la que aclara que al haber transcurrido el plazo legal de impugnación, "la difusión de la obra podría realizarse con toda normalidad" (expdte. n. ${ }^{0} 3017-$ 76), y además agrega que dos empresas -J. Porrúa Turanzas, S.A. y Francisco Expresate- habían solicitado importar ejemplares de Paradiso, frente a lo cual tampoco había "inconveniente en acceder a lo solicitado".

Finalmente, y aunque desde 1974 ya circulaban ejemplares de Paradiso de la editorial Fundamentos en España, bajo estas irregularidades legislativas, no fue hasta diez años después de la edición cubana, que se contó con una edición oficialmente autorizada, con lo que se cierran estos episodios.

Si bien, más allá de la carta inicial enviada por Viscaíno a Lezama en septiembre de 1974, no contamos con más documentación que registre un contacto directo entre la editorial y el habanero, mediante su correspondencia podemos observar que él no solo estaba al tanto de este proceso editorial, sino también de las respuestas de la censura. Así lo vemos, por ejemplo, en esta carta que le envió a su hermana Eloísa, en la que, tras enterarse de todas las trabas a las que su novela estaba siendo sometida en España, le expresa su desconcierto e indignación:

No sé por qué Paradiso no se ha podido publicar en España. Ahí se ha publicado Pantaleón y las visitadoras, que tiene muchas más cosas de intimidad sexual que las que 
conlleva toda mi novela. Y en una forma más descarnada y realista (1 de septiembre de 1974. Lezama, Cartas a Eloisa 184)

En esta misma línea, meses después -el 24 de enero de 1975- Lezama volvió a comentarle a su hermana que la publicación de su obra continuaba sin ser autorizada en la Península: "Me escribieron de Espańa, la editorial de que tú me hablabas, informándome de las dificultades que de nuevo tienen para publicar Paradiso. Parece que una censura seria vuelve a entronizarse en España. Claro, ellos no se quieren arriesgar" (Lezama Cartas a Eloisa 192).

No obstante, el cubano, siempre atento al devenir de sus obras y consciente de los perjuicios que tenía en relación a los derechos de autor -ya que la ley cubana impedía el pago a los autores correspondiente a las ventas-, así como del actuar de muchos editores que sacaban provecho de esta situación, estuvo al tanto que la edición de Fundamentos de Paradiso estaba en circulación, bajo una modalidad no del todo oficial, que él mismo llamó "pirata", y de la que, evidentemente, no recibiría ningún pago. Así se lo manifestó a su hermana el 13 de mayo de 1976: "En España se ha publicado Paradiso, ya lleva dos ediciones. Procura tú conseguir algún ejemplar de esa edición. Es una edición pirata, pero ese ha sido mi destino, vivir modestamente y que los demás se enriquezcan a costillas mías" (Lezama Cartas a Eloísa 206). Esta idea se la reiteró tres meses antes de su muerte, el 7 de junio de 1976: "Mi obra en el extranjero ha cambiado mucho, en Madrid se han publicado ya, como te dije en la carta anterior, dos ediciones de Paradiso. Tampoco me han llegado" (Lezama Cartas a Eloísa 208).

Es sabido que Lezama no se mostró inocente ante el actuar de los editores extranjeros y la situación legal en Cuba sobre los derechos de autor. En esta línea destaco la carta que le envió a su hermana el 5 de septiembre de 1974, en la que le dice que "lo más parecido a un editor es una sanguijuela o una piraña [...] se han aprovechado de que en Cuba no hay derechos de autor para llenarse los bolsillos a costa de mi trabajo intelectual", y le ejemplifica, entre otros, con el caso de su obra en Espańa, particularmente con el sello de Carlos Barral ${ }^{12}$. Además, - de acuerdo a las aclaraciones dadas por Eloísa a Lezama Lima en las notas de la carta- en esta epístola se da a entender que, al parecer, Alianza editorial también se había comunicado con él en algún momento, mostrándose interesada por publicar Paradiso, situación que no se formalizó:

la casa A [Alianza] dice vagamente que por la edición de Paradiso me pagarían una estancia en Barcelona. Otra picardía más, pues de sobra saben ellos que aquí no se autoriza la salida. [...] Todo lo calculan muy bien estas sanguijuelas. No obstante todo lo anterior dicho, puedes decirle a esa casa editora que publiquen la obra, haciéndoles

12 "Hablemos ahora de la editorial, [sic] que dice que está ligada a la casa B [Seix-Barral]. Tú recordarás que esta última casa editora organizó el concurso de poesía llamado Maldoror, premio que me fue otorgado. La medalla me la envió, pero el libro nunca se ha publicado. Dan disculpas, dicen que les mande poemas inéditos para que la edición les dé a ellos jugosos dividendos" (Lezama, Cartas a Eloísa 185). 
saber todo lo anterior, para que no crean que uno es un retrasado mental. (Lezama Cartas a Eloísa 185-186)

Tras la consulta del catálogo de los libros de la biblioteca personal del autor (albergados algunos en la Biblioteca Nacional de Cuba José Martí y otros en su casa Museo en La Habana), pude corroborar que entre los ejemplares que se conservan de Paradiso, en lengua castellana, solo se encuentran los de la editorial Unión (1966) y Era (1968), junto a tres traducciones: la francesa de Éditions du Seuil (1971), la italiana de Il Saggiatore (1971) y la norteamericana de Farrar, Straus and Giroux (1974). Es muy probable, por tanto, que el habanero falleciera sin conocer la primera edición de Paradiso en España -desconozco si porque la editorial no le escribió ni le envió ejemplares o si porque estos fueron requisados por la administración cubana, o por posible pérdida del ejemplar-. Todo ello es una muestra más de cómo se le sumó a su insilio insular el haber sido aislado también del propio proceso de publicación de su obra ${ }^{13}$.

\section{Intentos por visibilizar Paradiso en España}

No obstante lo anterior, en este tormentoso devenir de la novela Paradiso en la Península, hubo en esos años un par de gestos reivindicativos de la obra que contribuyeron a la visibilización de Lezama en España. Por su parte, la revista madrileña Índice en su número 232 (junio de 1968), tras la aparición de Paradiso en Latinoamérica, considerada como un "acontecimiento mayor de las letras hispánicas" (anónimo 21), decidió -tal como señala en sus páginas introductorias- rendirle homenaje "desde este lado del idioma a José Lezama Lima" (anónimo 21). En ese dossier aparecieron dos fragmentos de la novela (de los capítulos VI y IX), que son las primeras muestras en España de la obra, además de unos párrafos de, en ese entonces su novela inédita, Inferno (título que llevaba inicialmente Oppiano Licario). Estos segmentos fueron acompañados de textos de autores de ambos lados del océano dedicados a la figura del "peregrino inmóvil”, como lo llamó el escritor argentino Tomás Eloy Martínez. Entre ellos, "Una aproximación a 'Paradiso"” de César López -que vendría a ser el primer texto crítico en torno a la novela publicado en la Península; y de los españoles, el artículo "José Lezama Lima en La Habana", de María Zambrano, y el poema "José Lezama Lima”, de José Ángel Valente ${ }^{14}$.

13 En el Fondo Personal de Lezama se conserva una carta mecanografiada de Carlos Spottorno, fechada en Roma el 3 de agosto de 1976, en la que le comenta que le envía un ejemplar de la edición española de Paradiso, sin aclarar el sello editorial de esta. Ante la cercanía de la carta con la fecha del fallecimiento de Lezama (9 de agosto de 1976), deducimos que el cubano no alcanzó a leerla, y al menos en el catálogo actual de su biblioteca no se encuentra esta edición.

14 Los otros artículos que componen este dossier son: "El peregrino inmóvil" de Tomás Eloy Martínez, ya mencionado; "Lezama, de una vez", de Armando Álvarez Bravo; e "Introducción a José Lezama Lima” de Manuel Díaz Martínez. 
Poco tiempo después, la revista Ínsula dedicó su número 260-261 (julioagosto de 1968) a la cultura cubana, con el monográfico titulado "Cuba, hoy". En este, junto con la muestra de poemas de los cubanos Nicolás Guillén, Cintio Vitier, Fayad Jamís, Eliseo Diego, Roberto Fernández Retamar, y del propio Lezama; está el artículo "La novela cubana de hoy", en el que el crítico literario cubano Salvador Bueno le dedica unas breves líneas a Paradiso. Acompañan a estos textos, otros tres artículos en torno a la figura de Lezama de españoles que se sumaron a estos intentos por rescatar a su figura del silencio: "Cuba y la poesía de José Lezama Lima" de Zambrano, "Carta abierta a Lezama Lima” de Valente, y "Paradiso de José Lezama Lima" del crítico literario Jorge Campos, la primera reseńa espańola de la novela.

Por otra parte, ya desde el ámbito de las artes visuales, subrayo la breve exposición Paradiso, que José Luis Merino, director de la Galería Grises de Bilbao, montó en 1970, antes de que la novela pudiera ser publicada en el país. Esta consistió en la exhibición en las paredes del recinto de varias páginas de la obra, en los distintos idiomas -en ese entonces no oficiales- de España, entre otros; y en exhibir, en medio de la galería, un ejemplar de la novela para que fuera consultado por los visitantes. Lamentablemente, la exposición también fue víctima de la censura y tuvo prohibida su circulación por otras ciudades del país.

En una columna del blog del periódico El País, titulada "Portentoso Lezama Lima” del 14 de mayo del 2012, José Luis Merino, con un texto memorialístico, narró sus recuerdos sobre esa iniciativa:

Leí la novela Paradiso, del poeta cubano José Lezama Lima, con tan acucioso fervor que decidí montar una exposición sobre ella en mi galería. Corría el año 1970 [...] La muestra consistió en la transcripción de varias páginas de Paradiso en folios llevadas a las paredes [...] Entre esas páginas iban siete de ellas traducidas al inglés, alemán, francés, italiano, euskera, catalán y gallego. En medio de la galería, sobre un plinto, colgamos un ejemplar de Paradiso. [...]

Le hice llegar el catálogo de la exposición a Lezama Lima. [...] Al poco tiempo recibí una carta suya como respuesta. (Merino s/p.)

La noticia sobre esta exposición no le fue ajena al cubano, nieto de vascos, quien lleno de júbilo y alegría, no dudó en ponerse en contacto con Merino para agradecerle su labor y comunicarle su felicidad, sobre todo tras las desdichas y frustraciones que le habían implicado los "malos tratos" dados a su obra. Así se lo manifestó en una carta del 3 de junio de 1970:

Qué estallante fiesta de entusiasmo nos trae cada uno de sus avisos. Su acercamiento a Paradiso me rebosa de alegría, pues pocas veces se ve una respiración tan cordial en torno a un texto. Vale la pena recorrer las vicisitudes de una obra cuando sabemos que la habitan unos lectores nuevos que lanzan sobre ella y la vuelven a echar a andar en cada instante [...]. Mi abuelo, don José María Lezama y Tapa [...] era de Bilbao, así que los que creemos en lo invisible, lo hemos visto entrar en esa exposición y 
releer con ánimo complacido las páginas en las paredes de su nieto habanero. [...] Siempre hay una sorpresa, un maravilloso nacimiento que viene en nuestra ayuda. Su entusiasmo y su coraje han ganado por anticipado todas las sorpresas. (Lezama Cartas a Eloisa 406)

Por otro lado, como parte de la recepción crítica de la obra, rescato las palabras del crítico literario Juan Antonio Masoliver, en su reseña del libro Interrogando a Lezama, publicada el 29 de junio de 1972 en La vanguardia española. En ella, y haciendo un guińo a la colección de Tusquets, "Cuadernos marginales", donde se publicó Esferaimagen, lamentó la aún ausente edición española de Paradiso y valoró esas otras publicaciones que contrarrestaban el silencio de la obra del autor:

Mientras "Paradiso", una de las expresiones más altas de la novela contemporánea, sigue siendo tesoro para unos pocos, es de celebrar el esfuerzo de Ocnos, Tusquets o Anagrama por presentar distintos aspectos de la obra de Lezama Lima, aspectos que en ningún momento podremos considerar marginales en un escritor donde todo se integra en el conjunto de su obra para formar parte de una más enriquecida totalidad. (Masoliver 51; cursiva en el original)

Finalmente, el último registro que he podido cotejar en torno a Paradiso en aquellos ańos ${ }^{15}$, corresponde a la entrevista que le realizó el escritor y periodista Fernando Martínez Laínez, antecedida por una breve semblanza, publicada en abril de 1974, meses antes de que Fundamentos enviara los ejemplares a depósito, en el n. ${ }^{\circ} 604$ de la revista de oposición a la dictadura franquista, Triunfo, con el título "A todos soy deudor". Destaco de la respuesta que dio el cubano a la eufemística pregunta de por qué "no se publicó Paradiso en España", su enfático rechazo -no exento de ironía- a reprocharla por asuntos morales:

me dijeron que la obra no se publicó porque la habían censurado. Pero si eso es así, no sé cuál es el motivo de la censura, puesto que mi obra en el fondo no es más que una revitalización de los temas de Occidente, cuya raíz es innegablemente ecuménica, es católica.

Algunos insolentes han afirmado que en mi obra hay elementos pornográficos, pero eso no solamente es una injusticia, sino que puede ser hasta una canallada, [...]. Mi obra podrá ser censurada por sus defectos de estilo pero jamás por motivos éticos, puesto que su raíz es esencialmente la de un auto sacramental. (Lezama en Martínez 61)

\section{Paradiso libre de pecado}

No puedo cerrar este intento por reconstruir ciertos episodios del devenir de Paradiso en Espańa, sin señalar que no es más que una pequeña muestra de esa red transatlántica de mediadores culturales que participaron en la llegada

15 En el caso de ser así, sería la primera y última vez que los lectores españoles pudieron acceder a la palabra de Lezama, al margen de sus obras propiamente tal. 
de la obra lezamiana a la Península. Esta se enriquece, y debe complementarse, abordando también esas otras figuras que colaboraron y participaron, como, por ejemplo, los editores que durante esos años publicaron sus poemarios -sin liberarse de los censores-, junto a los intelectuales y críticos literarios españoles -como Joaquín Marco, J.A. Goytisolo, Jorge Herralde, en el caso particular de Lezama- que velaron por la divulgación y promoción de la literatura y cultura cubana e hispanoamericana en España mediante la publicación de ensayos, columnas, prólogos y reseñas de las obras, por lo que desempeñaron un importante papel en el cambio del panorama socioliterario español y en la internacionalización de las letras de ultramar.

El autor de Paradiso, al igual que Sarduy, Cabrera Infante y Pińera, entre otros, formó parte de esa lista de escritores que, por diversos motivos y de distintas formas, tuvieron una difícil asimilación por parte de la oficialidad cubana. En estas líneas he podido dar cuenta de cómo Lezama -pese a las diferentes medidas que recibió y que afectaron su participación en el sistema literario en lengua castellana, así como en el mercado de este (como lo fueron las constantes negaciones para viajar al extranjero, marginándolo en su propia tierra, y la propia censura de Paradiso) - desde su insilio en la calle Trocadero en La Habana vieja, logró hacer resistencia al ostracismo y conseguir una consagración internacional que no fue precisamente recibida con aplausos dentro de la isla.

De esta forma, aproximarnos a Paradiso implica atender a un campo cultural que, enmarcado en represión política y social, se caracterizó por la consagración de un aparato de mercadotecnia del libro transnacional y por la búsqueda tanto de un canon literario como de un proyecto ideológico, conduciéndonos así a un contexto de poéticas y políticas en disputa.

\section{Referencias bibliográficas}

Abellán, Manuel L. "La escritura franquista y los escritores latinoamericanos". Letras peninsulares, n. ${ }^{\circ}$ 5.1, 1992, pp. 11-21.

Bueno, Salvador. "La novela cubana de hoy", Ínsula, año xxıII, n.o 260-261, jul.-ago. 1968, pp. 1, 21 y 24.

Bustamante, Fernanda (ed.). El asmático insigne, monstruo de Trocadero. José Lezama Lima y José Agustín Goytisolo. Correspondencia y otros textos. Madrid, Verbum, 2017.

Campo, Jorge. “Paradiso' de José Lezama Lima”, Ínsula, año xxıı, n. o 260-261, jul.-ago. 1968, pp. 11 y 28.

Cortázar, Julio. "Para llegar a Lezama". Unión, n.o 4, oct.-dic. 1966, pp. 36-60. [También en Cortázar, Julio. La vuelta al día en ochenta mundos. México, Siglo XXI, 1976, pp. 135-155.] 
Fornet, Jorge. El 71. Anatomía de una crisis. La Habana, Ed. Letras Cubanas, 2013.

Lezama Lima, José. Cartas (1939-1976), Introducción y selección de Eloísa Lezama Lima. Madrid, Ed. Orígenes, 1979.

Cartas a Eloísa y otra correspondencia. Edición comentada e introducción de José Triana. Madrid, Verbum, 1998.

Martínez Laínez, Fernando. "Lezama Lima: a todos soy deudor", Triunfo, año XXIX, n. ${ }^{\circ} 604,27 / 04 / 1974$, pp. 56-61.

Masoliver, Juan Antonio. "Reseña: Interrogando a Lezama Lima”, La vanguardia española, 29 junio 1972, p. 51.

Merino, José Luis. "Portentoso Lezama”, Blogs El país, 14 mayo 2012. <http:// blogs.elpais.com/ladrones-de-fuego/2012/05> (enero de 2014).

Prats Fons, Núria. "La censura ante la novela hispanoamericana", en Joaquín Marco y Jordi Gracia (eds.), La llegada de los bárbaros. La recepción de narrativa hispanoamericana en España, 1960-1981. Barcelona, Edhasa, 2004, pp. 189-218.

Prats Sariol, José. "Paradiso: recepciones", y "Resúmenes críticos de los capítulos de Paradiso", en Lezama Lima, José, Paradiso. Edición crítica. Cintio Vitier (coord.), Madrid, ALLCA XX, Colección Archivos, 2017, pp. 565-589 y 661-662.

Rojas, Rafael. "Paradiso, el boom y la Guerra Fría”, en Aparicio, Yannelyz (ed.), Literatura y cultura cubana en tiempos de cambio. Madrid, Verbum, 2017, pp. 15-30.

. La polis literaria. El boom, la Revolución y otras polémicas de la Guerra Fría. Barcelona, Penguin Random House, 2018.

Sánchez, Pablo. Liturgias utópicas. La revolución cubana en la literatura española. Madrid, Verbum, 2012.

Tena Fernández, Ramón. "Reacciones de la Editorial Fundamentos ante la censura franquista: entrevista a Cristina Vizcaíno Auger", Revista chilena de literatura, nov. 2018, n. 98 , pp. 383-394.

Triana, José. "Introducción”, en Lezama Lima, José, Cartas a Eloisa y otra correspondencia. Madrid, Verbum, 1998, pp. 17-29.

Valente, José Ángel. “José Lezama Lima”, Índice, n.o 232, jun. 1968, año XxiıI, p. 30 .

. "Carta abierta a José Lezama Lima”, Ínsula, año xxiır, n. o 260-261, jul.ago. 1968, p. 3 .

Zambrano, María. "José Lezama Lima en La Habana”, Índice, n. ${ }^{\circ}$ 232, jun. 1968, año xxıII, pp. 40-42. 
. "Cuba y la poesía de José Lezama Lima”, Ínsula, año xxıII, n. o 260-261, jul.-ago. 1968, p. 4.

COMUNiCACión personal albergada en el Fondo personal José Lezama Lima. Sala Cubana, Biblioteca Nacional de Cuba José Martí

Fondo JLL-Bncjm: 655 / Carlos Barral [carta mecanografiada a J. Lezama Lima. Barcelona, 25/10/1966].

Fondo JLL-BNCJM: 1140 / José Lezama Lima [carta mecanografiada a Carlos Barral. La Habana, 03/10/1967. También en Cartas a Eloisa y otra correspondencia, 1998: 355].

Fondo JLL-BNCJM: 656 / CARLos BARRAL [carta mecanografiada a J. Lezama Lima. 27/05/1970].

Fondo JLL-BNCJM: 1212 / CARLOS BARRAL [carta mecanografiada a J. Lezama Lima. 31/05/1972].

Fondo JLL-BNCJM: 1213 / José LezAma Lima [carta mecanografiada a Carlos Barral. La Habana, 26/10/1972].

Fondo JLL-BNCJM: 657 / CARlos Barral [carta mecanografiada a J. Lezama Lima. Barcelona, 17/09/1973].

Fondo JLL-BNCJM: 1214 / José LezAma Lima [carta mecanografiada a Carlos Barral. La Habana, 31/10/1973].

Fondo JLL-BNCJM: 837 / CRistina VizCAino [carta mecanografiada a J. Lezama Lima. 13/09/1974].

Fondo JLL-BNCJM: 1.163 / José LeZAMA Lima [carta mecanografiada a José Luis Merino. La Habana, 03/06/1970. También en Cartas a Eloisa y otra correspondencia, 1998: 406].

Expedientes Archivo General de la Administración. Ministerio de eduCACIÓN, CULTURA Y DEPORTE DEL GOBIERNO DE ESPAÑA

N. o 9652-68 / J. Lezama Lima. Paradiso. Equipo editorial San Sebastián. N. ${ }^{\circ}$ 10321-73 / J. Lezama Lima. Paradiso. Barral editores. N.o 12628-74 / J. Lezama Lima. Paradiso. Editorial Fundamentos. N.o $13838-75$ / J. Lezama Lima. Paradiso. Editorial Fundamentos. N. ${ }^{\circ}$ 3017-76 / J. Lezama Lima. Paradiso. Editorial Fundamentos. 